This item was submitted to Loughborough's Research Repository by the author.

Items in Figshare are protected by copyright, with all rights reserved, unless otherwise indicated.

\title{
Falling off the bandwagon? Exploring the challenges to sustained digital engagement by older people
}

\author{
PLEASE CITE THE PUBLISHED VERSION
}

http://dx.doi.org/10.1159/000357431

\section{PUBLISHER}

(C) S. Karger AG

\section{VERSION}

AM (Accepted Manuscript)

\section{PUBLISHER STATEMENT}

This work is made available according to the conditions of the Creative Commons Attribution-NonCommercialNoDerivatives 4.0 International (CC BY-NC-ND 4.0) licence. Full details of this licence are available at: https://creativecommons.org/licenses/by-nc-nd/4.0/ This work is made available according to the conditions of the Creative Commons Attribution-NonCommercial-NoDerivatives 4.0 International (CC BY-NC-ND 4.0) licence. Full details of this licence are available at: https://creativecommons.org/licenses/by-nc-nd/4.0/

\section{LICENCE}

CC BY-NC-ND 4.0

\section{REPOSITORY RECORD}

Damodaran, Leela, Wendy Olphert, and J. Sandhu. 2019. "Falling Off the Bandwagon? Exploring the Challenges to Sustained Digital Engagement by Older People". figshare. https://hdl.handle.net/2134/16952. 
Title: Falling off the Bandwagon? Exploring the factors that can lead to digital disengagement by older people.

By L. Damodaran, C.W. Olphert and J. Sandhu, Loughborough University

Key words: older adults, ICT, digital technology, digital inclusion, disengagement.

Department of Information Science, Bridgeman Building, Loughborough University, Loughborough, Leics LE11 3TU.

E: c.w.olphert@lboro.ac.uk; l.damodaran@lboro.ac.uk;

T: +44 (0)1509 225914

Short title for use as running head: Falling off the Bandwagon? 


\begin{abstract}
Objectives

This study examines older people's use of information and communication technologies (ICTs) and identifies the factors which can prevent or promote their sustained use.

\section{Methods}

A mixed methods approach was adopted. Quantitative and qualitative data were collected by a survey of 323 older ICT users (aged 50+) between 2011 and 2012. These data were supplemented by qualitative data obtained through in-depth interviews, focus groups, and story-telling. Quantitative data were analysed using PASW including bivariate and multivariate analyses. Qualitative data were analysed using an inductive, thematic approach.
\end{abstract}

Results

The findings show that, contrary to some stereotypes, many older people are enthusiastic, competent and confident users of ICTs. However they report a range of challenges in reaching and maintaining this situation. These include technological complexity and change, age-related capability changes and a lack of learning and support mechanisms. Intrinsic motivation and social support are important in enabling older people to overcome these challenges.

Discussion

Getting older people online has been a high priority in many countries over the past decade. However, little attention has been paid to whether and how their usage can be sustained over time. We discuss the implications of the findings for policy and practice. 


\section{Introduction}

Older people represent a growing proportion of the world's population. By 2050, it is projected that a fifth of the worldwide population will be aged over 60 [1], and in some countries the proportion of older people will be even greater. For example by 2034, it is projected that almost a quarter of the population of the United Kingdom (UK) will be aged over 65. This demographic change brings many challenges to society, including maintaining the health and independence of older people and ensuring that they are able to participate fully in society.

Digital technologies - in particular computers and the internet - are widely expected to have a role to play in responding to these challenges. There is increasing interest in the exploitation of digital technologies specifically to deliver care and health monitoring services for older people [2]. Digital technologies also provide access to an ever-increasing range of information, goods, services, entertainment/leisure, educational and social networking opportunities that can help older people to maintain their independence and social connectedness and to improve their quality of life. If older people are 'digitally engaged' i.e. have access and the ability to use digital technologies - there are opportunities to reduce the so-called 'burden of care' associated with an ageing population, and to achieve wider benefits from their ability to participate socially and economically [3]. Furthermore, since government as well as commercial services are increasingly being delivered online, it is recognised that older people who are not digitally engaged will not only fail to enjoy the advantages, but may be at risk of real economic and social disadvantages [4]. Yet despite the potential benefits of digital engagement, many older people have been relatively slow to adopt the internet, compared to younger generations. Recent studies [5 \& 6] report that while 80 per cent or more of the total population in Britain and the US regularly use the internet, this figure drops to fewer than 40 per cent among older people.

It has been suggested that this so-called 'grey digital divide' [7] will eventually close, as people who are established computer users move into retirement, or as a consequence of the many initiatives and programmes designed specifically to encourage and teach older people to use computers and the internet, or perhaps as a consequence of improvements in ease of use and accessibility of the technology. Certainly there are growing numbers of older users; in the UK for example the over 75s are reported as being the fastest growing group of internet users in 2010 [8] although the percentage is still small compared to younger users. 
However it has also been suggested that older users may face particular difficulties and challenges in using ICTs effectively which could make it difficult or even impossible for them to continue sustained usage [9]. Data from various surveys indicate that between $3 \%$ and 39\% of users may give up using their computers at some point and for some period of time, and suggest that older and disabled people are more likely to give up than other categories of user. Some reasons for the wide divergence in the statistics are discussed in [4] but primarily relate to differences in the length of time used as an indicator of disuse, which ranges from one month since last use to one year. The study with both the largest sample size $(25,169,820)$ and longest interval since last use (one year) show that while around $3 \%$ of the population as a whole may give up using their computers, this rises to almost $10 \%$ of older and disabled users [10]. Such an attrition rate raises concerns: achieving the benefits of digital engagement requires not only that people join the 'bandwagon' of digital engagement, but also that they sustain that engagement on an on-going basis. Yet to date most studies of older adults' computer use have focussed on understanding the factors which prevent or promote initial adoption [11,12], and there has been little research to understand the challenges associated with sustaining use of computers and the internet by older people

This gap in knowledge has important implications at both policy and practical levels. Knowledge of the risk factors which could lead to disengagement could, in turn, lead to the development of social and technical solutions which could help to reduce or prevent such an outcome. Better understanding of the scale and nature of disengagement, on the other hand, could help to inform the development of facilities and services which support and do not exclude those who are not able to access them online.

The overall aim of the [name of] research project [9] was to address this gap in knowledge by investigating the problems and support needs of older users of computers and the internet. and This project was a three year, multi-disciplinary collaborative research project involving a team of academics from eight universities across the UK. It was funded by the UK Research Councils as part of the New Dynamics of Ageing research programme - the largest and most ambitious programme of research on ageing ever mounted in the UK, with the aims of improving the quality of life of older people [13].

In this paper we report quantitative and qualitative data gained about the problems and challenges faced by older people as computer users, and discuss the findings and their implications. 


\section{Methodology}

\section{(i) Research approach}

A key underpinning principle of the [name of] project was that the research should be participatory, i.e. involving and engaging with older people as active participants and coproducers of knowledge, rather than as subjects of the research. To reflect this principle, and to fulfil the objectives of the research, a range of data collection approaches and tools were designed with the aims of both generating quantitative and rich qualitative data and enabling engagement with a wide and diverse sample of older people. To collect breadth and depth of data about older peoples' usage and experiences of digital technologies in general and computers and the internet in particular, the methods used included questionnaire-based surveys, individual interviews and observations, focus groups, case studies, and storytelling. To involve and engage older people in defining, developing and exploring potential solutions to the challenges of using digital technologies, methods included workshops, co-design 'sandpits' and trials and evaluation of prototype technologies. The research approach and individual data collection tools were approved by the Ethical Committees of the Universities who took part in the project.

For consistency with the programme sponsoring the research, older people were defined as those aged 50+. To reach older adults in all their diversity, the researchers worked collaboratively with individuals drawn from 33 existing groups/panels of older people in communities across the UK (see table 1). In total more than 1000 older people have participated in one or more of the project activities during the course of the project. The relationship with the participants and groups was maintained and nurtured over the duration of the project, and in many cases is on-going.

Each of the data collection methods used, together with details of the sample, recruitment strategy and data analysis approach, are described briefly below.

\section{Table 1}

(i) Questionnaire Based Survey 
Questions for the survey were developed around key factors identified from review of the literature and previously reported surveys of older peoples' use of digital technologies. Questions about ICT usage were taken, with permission, from a survey tool designed by researchers on the SIDE project [http://side.computing.dundee.ac.uk/], to allow for the possibility of future comparative analyses with data being collected about digital engagement from a broader age range. The questionnaire included a mixture of closed and open ended questions, covering the following topics: duration, frequency, scope of use and confidence levels in using computers and the internet and specific applications and functions; location of use; the types of training and learning participants had received, availability and use of help and support mechanisms; awareness and use of accessibility features on the computer; motivation and attitudes towards using computers and the internet; and challenges and problems encountered. A separate questionnaire collected demographic data about participants, including age, gender, ethnicity, employment status, educational background, marital status, and housing situation. These characteristics have all been identified from the literature as potential moderating variables influencing older peoples’ digital engagement.

The questionnaire was printed in 14pt type to aid reading and designed to enable data to be entered using optical mark reading equipment. The questionnaire was piloted extensively with older people and revised in the light of their feedback.

Participants were recruited from the 24 groups identified in table 1. Recruitment criteria for the survey required that participants were aged $50+$, and had used a computer for two years or more. A total of 323 people participated in completing the questionnaire.

Responses to closed questions were coded and analysed using the PASW software package. For the open questions, a thematic approach to analysis was undertaken. In thematic analysis the task of the researcher is to identify a limited number of themes which adequately reflects textual data [14].

\section{(ii) Methods for collecting in-depth qualitative data}

Over the course of the project, members of the research team based in different universities in different geographic locations in the UK engaged with their local groups and communities of older people in a variety of activities that provided the opportunity to collect rich qualitative data about their experiences as computer users. While the nature of each activity was 
different, the themes that were explored were common to all: the motivations of the participants for using computers, their learning journeys, the nature of their experiences as users, including benefits and obstacles encountered (and ways of overcoming them), and sources of support. All participants had previously taken part in the questionnaire-based survey, and were recruited after indicating on the questionnaire their willingness to participate in further data collection activities.

In depth interviews were held with 16 participants. These involved face-to-face or telephone discussions between an individual participant and a researcher, typically lasting between half to one hour, based around open-ended questions. Eleven of the interviewees were volunteers drawn from attendees at a community centre in the north-east of England offering IT training and learning and other facilities. Five interviewees were volunteers drawn from service users of a local authority which provided ICT training and support services in the midlands. The age range of the interviewees was ranged from 51 to 88 years of age; twelve were females and six were males. eight were aged 50 - 64, fifteen were aged 65 - 80 and five were aged $80+$.

Focus group sessions were conducted in three locations with a total of 28 participants. One was held in the east of England, one in the midlands and one in Scotland. Each focus group involved 9-10 participants and was facilitated by a member of the research team. Focus group discussion sessions lasted for approximately one and half hours. Participants were drawn from volunteers at local computer clubs. The age range of participants was between 50 and 80+; eight were aged 50 - 64, fifteen were aged 65 - 80 and five were aged 80+. Sixteen participants were females and 12 were males.

'Storytelling' was used as a data collection technique with seven participants. This was a structured activity in which volunteers from local community organisations in the midlands of England were invited to recount in their own words how they had become 'digitally engaged' and describe their motivations, achievements and obstacles to an audience of older people, third sector service providers and representatives of local government. This took place as part of a community event aimed at promoting awareness of the benefits of digital inclusion and local online services. The age range of the participants was 50 to 76; two were aged 50 - 64 and four were aged 65+; four were females and three were males.

The content of the interviews, focus group discussions and storytelling sessions were recorded verbatim. The recordings were transcribed and the transcripts were then analysed 
using content analysis methods which allow for the interpretation of the content of data through the systematic classification process of coding and identifying themes or patterns [15].

\section{Findings}

This section reports the results from the analysis of data collected using the mixed methods described above.

\section{i) Demographic characteristics of participants}

Of 323 participants, two-thirds were fully retired (66\%), 25\% worked part time and 14\% worked full time. The average age of participants was 67 with a standard deviation of 0.86 . A breakdown of participant ages is detailed in table 2 below.

\section{Table 2}

The sample group was fairly representative of the UK population [16]. Of the 323 participants in the survey $49.5 \%$ were female and 50.5\% male. Recent UK Census statistics (ONS, 2012) report the UK population to be $49 \%$ male, 51\% female.

A larger proportion of the sample group were home owners. Almost $80 \%$ of participants were living in their own home and $20 \%$ were in rented accommodation. UK population statistics relating to home ownership show that two-thirds of the UK population (64\%) owned their own home and one third of the UK population (36\%) were residing in rented accommodation.

The majority of the sample group were white (80\%) compared with (86\%) of the UK population. The sample group was slightly over representative of ethnic minorities. For instance, $13 \%$ of the sample group were of Asian origin, 3\% were black, and 3\% were of a dual- heritage background. UK Census statistics (ONS, 2012) show that $7.5 \%$ of the UK population are Asian 3.3\% is of Black/African/Caribbean/British Black descent, 2.2\% are of a dual-heritage background and 1\% categorised themselves as other.

Almost half of the sample group were married (49\%), compared with $48.2 \%$ of the UK population (ONS, 2012). The sample group was slightly under-represented in terms of those who were single (20\% cf $35.6 \%$ ) or separated, divorced or widowed (30\% cf $16.3 \%)$. 


\section{ii) Use of ICTs}

\section{Number of technological devices used}

Participants in the survey were required to be established computer users. However the data show that in addition to using the computer, the majority of participants used a wide range of other digital devices, with $60 \%$ of respondents reporting using between 4-7 digital devices,. Approximately 20\% used 1-3 digital devices and approximately 20\% used 7-12 digital devices. The most common digital devices used by participants included mobile phone, desktop computers, laptop computers, digital camera, CD/DVD player, a set top box (e.g. to access digital TV) and satellite navigation. Less commonly used devices included MP3 player, games console, E-book reader, digital camcorder and tablet computers.

Frequency of use

Results from the survey show that the majority of older people used a wide range of digital technologies on a regular basis. Almost $80 \%$ used a mobile phone daily or several times a week and almost $70 \%$ used a computer daily or several times a week.

Tasks undertaken using the computer

Participants reported undertaking a wide range of tasks using computers or laptops including preparing documents, communicating with family and friends, searching for advice, shopping online and for information relating to hobbies and interests. As can be seen from Figure 3, the majority used their computers for 6-20 tasks (51\%); more than a third of respondents used their computers for 5 or fewer tasks (31\%), and almost a fifth of participants used their computers for more than 20 different tasks (19\%).

\section{Figure 3}

The most common tasks carried out regularly by participants using the computer were as follows:

- $\quad$ price comparison (65\%)

- seeking information on hobbies/interests and leisure activities (56\%),

- digital photo storage (54\%) 
- seeking health related advice (53\%),

- $\quad$ seeking weather information (52\%)

- $\quad$ seeking travel-related information (51\%)

- $\quad$ communicating by email (39\%)

Range of skills

While some older people only learn the basics associated with specific tasks relevant to their everyday lives, others will go on to master the use of digital technology for a wide range of tasks. Although the oldest group in this survey sample (80-89 year olds) tended to use their computers for fewer tasks, around $50 \%$ of the $60-80$ year olds used their computers for the wide diversity of tasks listed above. Some have developed in-depth expertise using particular software relevant to their pursuit of hobbies and interests, such as photography. Further, a third of respondents were keen to extend their current use of digital technologies.

\section{iii) Motivating factors in ICT use}

Data from the survey show that the main motivation for individuals was to learn for personal development reasons and to 'keep up with the times' (39\%). Around a quarter of participants were motivated to use the computer for work-related reasons (24\%). Other motivators were to gain access to information for various purposes (11\%) and to communicate with friends and family via email/Skype (11\%). Around ten per cent of respondents were encouraged to start using a computer by friends and family.

\section{iv) Learning and support experiences}

Over half of participants who completed the digital engagement survey reported learning to use technologies such as the computer on their own (i.e. by self-instruction or trial and error $54 \%)$ and just under half had been instructed by a personal teacher or trainer (47\%). Twofifths of participants learnt to use technologies with other people in informal situations (i.e. with friends and family - 40\%), or through a moderated web course (40\%) or in virtual situations (40\%). Over a third of participants also reported learning to use technologies using software tutorials (38\%) (e.g. camera software).

In answering a survey question about the most important thing to help participants to use technology successfully, over half stated support-related factors (56.2\%) as being important. Support-related factors included those related to human help and encouragement (i.e. friends, 
family, and tutors) (25\%), the availability and provision of help in classes/drop in centres (22\%), the quality of tutors and teaching environment (15\%), the availability of well written guides and help information (9\%), and the availability of expert advice (i.e. technical support) $(1 \%)$.

The importance of face-to face support is confirmed by responses to a survey question asking how often participants used different forms of support (see table 4). It is clear from responses that participants were more likely to seek face-to-face support such as asking friends and family or staff at computing class rather than consulting/seeking help from the Internet, operating system help files, books, software help files or from social networking.

\section{Table 4}

\section{v) Challenges in ICT use}

Of the 323 participants who completed the Digital Engagement Survey, 46\% answered an open-ended question relating to aspects of the computer which were difficult to use. Data from this survey question show that the challenges most frequently reported by older computer users were: a lack of technical skills/knowledge to do specific tasks or to solve problems when they occur (28\%); physical difficulties - for example using the mouse or keyboard, or seeing the screen (19\%); remembering things - for example passwords, or all the steps in a process (16\%); not knowing how to deal with computer security, especially how to deal with/prevent unwanted content such as viruses, pop-ups and spam (16\%); understanding technical ‘jargon’ (13\%); and problems with technology (10\%) (E.g. slow computers, blue screen errors, hardware/software incompatibilities).

\section{Discussion}

The findings above provide quantitative data on many aspects of digital engagement of older people. In this section, the qualitative data from the different methods described above are discussed to inform understanding and provide new knowledge about the nature of the user experience and particularly about the challenges faced by older computer users which may jeopardise sustained use. 
In order to preserve anonymity, in the discussion below individual participants are only identified by a number and code related to the location and method of data collection as follows:

\section{Table 5}

\section{Perceived Rewards and Benefits of using ICTs}

Qualitative data from focus groups, interviews, storytelling and case studies show that older people value very highly the benefits and independence that result from their use of ICTs. For some, it is seen as a basic skill and an important aspect of being able to participate fully in society. As one respondent put it, 'I feel that if I cannot use modern communication technology it would be similar to being unable to read' (Salt, P7, Int.) Many participants described using ICTs to make the mechanics of daily life easier and valued their benefits in terms of saving time, effort and money. However, the more powerful drivers for continued use of ICTs tended to be those associated with 'feel-good' activities perceived by the participant as beneficial to health and quality of life. These included 'stimulating the brain', 'feeling part of the 21st century', keeping in contact with family and friends, using ICT to enable the pursuit of passions and interests such as digital photography, creative writing, or listening to music. For instance, in the words of one participant:

'It thrills me to download music and listen to music. If I'm feeling low, music will lift me up ... it thrills me to write presentations attended by hundreds of people and get good feedback’. (Mid, P3, Int.)

Another participant reported that after a serious accident which left her severely incapacitated (wheelchair user and chronic pain sufferer), she felt she had "lost everything" and was very isolated. Learning to use ICTs helped her regain her independence, self-respect and helped to improve her quality of life. She described her current state of mind as 'my brain is waking up' and said that 'all this is connected to computers and information'..... She also commented that she is better off now, financially and emotionally, by virtue of all the information she got from the Internet, which enabled her to apply for disability grants, and not feel 'like you're separate from your community'. Information and access to a computer has really changed her life - 
'Before, I had lost me, lost everything ...now, I feel quite normal again. I'm doing something I would do if I wasn't disabled'. (Mid, P5, Int.)

\section{Challenges and Frustrations of ICT use}

Despite the high value often placed by older people on being able to interact with computers and the benefits that can ensue, participants also reported a number of frustrations and barriers in computer use and online activities. The qualitative data relating to these issues gained from the different research methods provide insight and understanding into the nature of the challenges and their implications, and informs solution generation.

\section{(i) Lack of technical skills/knowledge}

Software updates proved to be particularly problematic as exemplified by the following comment: 'I am usually cautious and may say no to a question about licensing agreements, but of course I needed to select yes to install the products. It is not having the knowledge that is the problem; I mean are you supposed to learn these things, in a classroom?' (Mid, P.8, FG)

Frequent, unprompted, automatic requests to update software that appear for no apparent reason to the user, and major upgrades such as new operating systems, combine to contribute to users feeling they are not in control of their interaction with the technology. Their comments make clear for example, that such 'upgrades' are in reality often experienced as retrograde in the 'de-skilling' effect they have in making hard-won skills redundant.

Further, the result of a lack of awareness for the need to carry out simple maintenance - and the lack of the skills to do so - can create significant barriers to use. In the event that the solutions are shown to be simple (i.e. 'simple if you know how'), this reduces the user's confidence in his/her own capabilities. For example, how to change settings on the computer to get larger icons and bigger text is not immediately obvious to most users - and the existence of such adaptive functions that do exist may not be pointed out in learning opportunities open to older people. This is more likely to be the case when the tutor is younger and not aware of such incapacities.

The findings show that the resultant usefulness and acceptance of adaptive software is influenced by the user's level of awareness of the concept of adaptation. There was generally 
a low level of awareness of the existence of adaptive functions. Even when users are aware of these, the use of such features presents issues of their own, in setting up and ease of use, including the level of control over suggested adaptations and confidence that use will not adversely affect task performance.

\section{(ii) Physical difficulties}

Some participants reported physical difficulties in using a computer, such as problems in using the mouse: 'Have arthritis in my hands so typing is difficult and I have to operate mouse in one hand and click with the other hand.' (P.197, DE.)

'My physical disability with my hand at the moment...makes the mouse hard to use.' (P.46, DE.)

Other comments included 'keyboards are too cramped and with my arthritic hands it is sometimes difficult to use' (P.152, DE). Deteriorating eyesight was problematic for other users. For example, one case study participant who eventually disengaged from using the computer found it too difficult to use it without assistance as his eyesight deteriorated and he would wait until one of his family members were there to help him or to do tasks on his behalf (Mids, P3, Int).

\section{(iii) Remembering things}

Some participants gave examples of limitations of working memory which made it difficult to remember passwords or to recall sequential steps in an operating procedure. These were perceived to be a serious obstacle to their use of ICTs. In interviews, focus groups and storytelling, comments such as the following were made repeatedly: 'not remembering it at our age' (Dun, P.6, FG), 'I might need reminding' (Salt, P.3, Int), 'the memory isn't as sharp as it used to be' (Mid, P.15, FG) and 'I struggle a lot to remember things' (Mid, P1, FG). Frustrating difficulties in remembering sequential processes and the content taught in class were summed up by one participant as follows: 'I learn how to do it in class. By the time I get home, I've forgotten it all' (Mid, P.8, FG). The value of writing instructions was reflected in the comment: 
'It [memory] goes when you get to our age, it doesn't stay in but if you have got it written down then it comes back to you because you have got the written word to refer back to’. (Salt, P.3, Int)

\section{(iv) Computer security and unwanted content}

Not knowing how to deal with/prevent unwanted content such as viruses, pop-ups and spam were frequently-voiced problems exemplified by one participant's fear of inadvertently downloading viruses:

'I'm worried about downloading a virus because people send out viruses and unless you know what to look for as to whether it is likely to be a virus...it is worrying... I think viruses and things can get in easy through Skype’. (Salt, P.9, Int.)

\section{(v) Technical jargon}

Terminology was characterised as 'baffling' and instructions were found to be 'incomprehensible and confusing'. Common complaints by participants included ' $I$ don't understand computer language' (P.188, DE), 'the language \& abbreviations is confusing' (Dun, P.3, FG) and 'computer language is always a barrier' (Mid, P.16, FG).

\section{(vi) Problems with technology}

Issues with technology were reported to be problematic. Some participants spoke of their computers being 'slow and freezing' (P.202, DE); using a slow computer was experienced as disruptive to the task in hand and time wasting. Others spoke about specific hardware technical errors, i.e. “serious system problems” (P.167, DE), “blue screens” (P.164, DE) and “having to go into DOS” (P.221, DE).

Using public access computers often causes further barriers to usage. Such systems may be 'locked down' so that the user cannot make changes e.g. to make font size larger or other 
adaptations to improve accessibility. In other situations, when such changes are made, they only last for the duration of each particular user session as functions revert to their defaults at the end of the session.

In summary, two key determinants of user experience emerge from the findings: (i) characteristics and features of the technology itself, and (ii) the quality and availability of ICT learning and support. This understanding is informing solutions, as discussed below.

\section{Characteristics and features of the technology}

With regard to the technology, the findings presented above indicate clearly that there are many aspects of technology which older people find difficult or baffling, suggesting there is much scope for improvement in the design of technologies to be used by older people. There already exists an extensive body of knowledge available to designers from research which has established the characteristics and features of ICT-based products and services that will make them easy to use and accessible. Some of this indeed has been codified into international standards (such as ISO 9241 'Ergonomics of Human System Interaction’. There is also a growing body of knowledge about the specific needs and capabilities of older computer users [17] to which other aspects of this project have contributed, for example, providing insights into the role and enthusiasm of older people to shape the design of digital devices through their participation in 'sandpits' or co-design workshops. Further consideration of these aspects is beyond the scope of this paper and is published elsewhere. For example, the outcomes have been documented in a Design Concept catalogue of 40 innovative product concepts [18]. This catalogue, intended for ICT innovators, designers and developers, serves to stimulate new ideas for products aimed at the older market that are based on older peoples’ interests, needs and preferences.

\section{Role of support and deficiencies in provision}

Although some of the frustrations and difficulties reported by participants in this study may be reduced or avoided through improved design, given the diversity of skills and capabilities amongst older people as well as the diversity and complexity of technology and the rapid rate of change and development, there is likely to be an on-going need for learning and support. Older people report wanting help and sympathetic support on demand and at point of need. All participants stated that they valued timely support to solve technology related 
problems - especially those associated with cross-platform issues and other troubleshooting needs. The need for effective trouble-shooting when things go wrong is particularly acute.

'Whatever crops up on the screen, you seem to have got yourself in a mess is when you get unravelled, it happens too quickly, you don't understand what happened and how to put it right ... that leaves me baffled' (Mid, P1., FG)

Participants reported unsatisfactory attempts at trial and error problem solving on their own or accessing telephone helplines or online support. With telephone helplines, some older users found that they were unable to get through while others complained of not being able to get the right kind of support.

'After an extremely expensive phone call to a call centre and a whole day spent trying to get hold of the right person, they established the computer needed repairing and needed to be taken away.' (Dun, P.10, FG)

Manuals were often considered to be 'incomprehensible', while generic 'how to' books offered limited assistance in solving technical problems. In addition, both sources could quickly become outdated as technology moved on.

'Books are particularly difficult to understand and often out of date as technology has moved on by the time the books are published and accessible in a public library’ (Mid, P.15, FG)

While help and support are perceived as highly important to older ICT users, their needs are far from adequately met: the availability of learning and support provision designed specifically for older people is varied and 'patchy' across the UK [19]. Provision for sustaining their use and engagement with ICTs is even scarcer than provision of initial training. Information about support options, including aids to accessibility, typically does not reach those who need it. Many prefer learning and support opportunities to be embedded in social processes in the pursuit of personal passions and interests (i.e. purposeful social interaction in ICT-enabled activities of personal relevance and significance rather than seeking qualifications or skill development per se). More readily available course or qualification based learning in Adult education services is less helpful.

The contrast between the support available for ICT users at home, often alone, with that available to users in the workplace, is stark. ICT users in the workplace often have an 
extensive range of support to help them resolve problems and maintain their skills, while older people (and others) outside the workplace must fend for themselves. This means having to rely on whatever support they can find from friends and family or in the community and, typically, experiencing the associated frustration:

"My son ... hasn't got the time to sit with me and talk me through things. That's why I really need to get involved, learning more about the computer. I feel left behind. I don't like that much.” (Dun, P.1, FG)

For those participants who report a lack of comprehension and/or ICT skills to understand the task being undertaken or encountering a range of technological problems, appropriate support to help resolve the technical problem is critically important in enabling participants to overcome their problems and continue to use technology successfully.

The value placed on ICT skills and especially knowledge of computer maintenance expertise e.g. the capability to carry out defragmentation of files, argues for training in generic transferable skills. For example, there would be great benefit in helping older people to develop appropriate mental models [20] to enhance their understanding of ICT through the explication of principles, processes and strategies including common screen or touch screen navigation conventions and understanding the key functions of software such as operating systems and word processors. Internalising such knowledge would allow them to transfer their understanding to the next generation of technologies.

As older people in the UK will soon only be able to access some government services online, this suggests that the significant gap in support provision identified by this research needs to be addressed as a matter of urgency. There is also a significant issue of affordability for some older people. The point is well-illustrated by the following comment:

“... there are no facilities available for me as a pensioner to learn this new skill unless I can pay for it” (Helen aged 59).

While there is scope to develop ICTs which are easier to use and present fewer technical challenges, one practicable solution to help users with problematic tasks such as installing spam filters, virus checkers etc. would be to make such a service available in local communities at drop-in centres and other venues offering ICT learning and support. Help of this kind is available in a few venues but is far from being a reliable and affordable service available to all older ICT users. 
The authors argue that current initiatives and strategies which focus primarily on introducing older people to ICT use will not on their own close the 'digital divide', nor will they remove or reduce the risks of disengagement since-they fail to address most of the challenges identified in this paper.

\section{Conclusions}

The realities of digital engagement of older people and the difficulties they have in sustaining it may undermine - or at best slow down - progress on the digital inclusion agenda and the implementation of digital strategies such as that of the UK Government. To address the issues will require coordinated policies, strategies and practices which extend from central government across local government, the third sector and the business sector. Much of the know-how required to address the shortcomings is already available from the outputs and outcomes of major publically funded research programmes in the UK and other countries. Exploiting this expertise to make major changes which are appropriate and relevant - and sought by many older ICT users - and has the potential to deliver inclusive connected nations. Thus the emerging findings have significant implications for designers, developers, learning and support providers, and policy makers for all nations with a growing older population.

In conclusion, the evidence presented in this paper shows that while many older people enjoy the benefits of information and communications technologies, their user experience is characterised by many challenges described earlier in this paper. Without support in dealing with these challenges, these problems can become overwhelming for individuals - especially those who are coping alone or with limited and unreliable sources of assistance. Yet, appropriate design of the technology and good support can mitigate the negative impact and promote successful and continued digital engagement of older people. 


\section{Acknowledgements}

Sus-IT ("Sustaining IT use by older people to promote autonomy and independence”) is a New Dynamics of Ageing (NDA) project, funded by the five UK Research Councils AHRC, BBSRC, EPSRC, ESRC and MRC (Grant No. RES-353-25-0008).

\section{References}

[1] UNITED NATIONS (UN): World population aging 1950-2050. New York: United Nations, Department of Economic and Social Affairs; 2006.

[2] WANGBERG SC, ANDREASSEN HK, PROKOSCH HU, VAGOS SANTANA SM, SØRENSENT, CHRONAKI CE: Relations between Internet use, socio-economic status (SES), social support and subjective health. Health Promot. Int. 2007: 23:1; 70-77.

[3] BRADSHAW H M: Digital Inclusion: Economic and social benefits for individuals and wider society. Social research report No. 26, 2011, produced for the Welsh Government. Available from:

http://wales.gov.uk/topics/housingandcommunity/research/community/econsocial/?lang=en [accessed 22.03.13]

[4] OLPHERT CW. \& DAMODARAN L: Older People and Digital Disengagement: A Fourth Digital Divide? Gerontology, 2013. In press

[5] DUTTON W H, HELSPER E J, GERBER M M: The Internet in Britain. Oxford Internet Survey 2009 Report. Oxford: Oxford Internet Institute, University of Oxford; 2009.

[6] DUTTON W H, BLANK G: Next Generation Users, The Internet in Britain. Oxford Internet Survey 2011. Oxford: Oxford Internet Institute, University of Oxford; 2011.

[7] MILLWARD P: The 'grey digital divide': Perception, exclusion and barriers of access to the Internet for older people. First Monday 2003: 8, 7. http://www.firstmonday.org/htbin/cgiwrap/bin/ojs/index.php/fm/article/viewArticle/1066/986 (accessed 6th June 2011) 
[8] OFCOM: Communications Market Report, UK. 2010. London: Ofcom. http://stakeholders.ofcom.org.uk/binaries/research/cmr/cmr11/UK_CMR_2011_FINAL.pdf

[9] DIGITAL INCLUSION PANEL: Enabling a Digitally United Kingdom: A Framework for Action, Cabinet Office, London. 2004.

[10] YOUNG W, KLIMA G, GADAG V, GIEN L, AND HARDILL I: Sustaining Information and Communication Technology use among Canadians with at Least One Activity Limitation. The International Journal of Technology, Knowledge and Society 2012; 7,1: 1-12.

[11] GATTO SL \& TAK SH: Computer, internet and e-mail use among older adults: benefits and barriers. Educational Gerontology 2008; 34: 800-811.

[12] SELWYN N: The Information aged: A qualitative study of older adults' use of information and communications technology, Journal of Ageing Studies 2004; 18: 369-384

[13] NDA Website: http://www.newdynamics.group.shef.ac.uk/ (accessed 11.12.12).

[14] THOMAS DR; A General Inductive Approach for Analyzing Qualitative Evaluation Data. American Journal of Evaluation 2006; 27 2: 237-246.

[15] HSIEH HF \& SHANNON SE: Three approaches to qualitative content analysis. Qualitative Health Research 2005; 15 9: 1277-1288.

[16] ONS: UK Census Population Statistics 2012 http://www.ons.gov.uk/ons/taxonomy/index.html?nscl=Population (accessed 22.06.13).

[17] SARA J. CZAJA AND CHIN CHIN LEE. 2002. Designing computer systems for older adults. In The human-computer interaction handbook, Julie A. Jacko and Andrew Sears (Eds.). L. Erlbaum Associates Inc., Hillsdale, NJ, USA 413-427.

[18] FROHLICH D, LIM C, WOOD S. AND AHMED A: What people want: a catalogue of co-designed ICT concepts. 2012. Accessible via http://sus-it.lboro.ac.uk/SusIT_DWRC.pdf [19] RAMONDT L, SANDHU, J \& DAMODARAN L: Staying digitally connected - a study of learning and support provision for older people in seven cities in the UK and the 
implications for policy and practice. Int. Journal for Education and Ageing 2013: 3 2. In Press

[20] GETNER D \& STEVENS AL: Mental Models. NJ, Erlbaum. 1983.

TABLES:

\begin{tabular}{|l|c|c|}
\hline \multicolumn{2}{|c|}{ TABLE 1: Sample, methods and numbers of participants } \\
\hline Name of Group & Data collection details & $\begin{array}{l}\text { Number of } \\
\text { people who } \\
\text { participated }\end{array}$ \\
\hline
\end{tabular}




\begin{tabular}{|c|c|c|}
\hline & & $\begin{array}{l}\text { in data } \\
\text { collection } \\
\text { activity }\end{array}$ \\
\hline \multicolumn{3}{|c|}{ Older peoples organisations } \\
\hline Age UK Nottingham & $\begin{array}{l}\text { Sample: All visitors at local AGE UK branch } \\
\text { targeted } \\
\text { Method: Sus-IT digital engagement survey }\end{array}$ & 29 \\
\hline $\begin{array}{l}\text { Age UK, Derby and } \\
\text { Derbyshire. }\end{array}$ & $\begin{array}{l}\text { Sample all computer users targeted } \\
\text { Method: Sus-IT digital engagement survey, } \\
\text { interviews }\end{array}$ & 16 \\
\hline Age UK, Leicester. & $\begin{array}{l}\text { Computer groups targeted } \\
\text { Method: Sus-IT digital engagement survey, story- } \\
\text { telling interviews }\end{array}$ & 110 \\
\hline AGE UK Barnet & $\begin{array}{l}\text { Sample: established (2+ years) computer users } \\
\text { recruited } \\
\text { Method: Sus-IT digital engagement survey }\end{array}$ & 8 \\
\hline Age Concern Guilford & $\begin{array}{l}\text { Sample: computer and non-computer users } \\
\text { targeted } \\
\text { Method: Sus-IT digital engagement survey }\end{array}$ & 16 \\
\hline $\begin{array}{l}\text { Age Concern Hackney - } \\
\text { Silver Surfer Agewell } \\
\text { Computer Club }\end{array}$ & $\begin{array}{l}\text { Sample: All members of the group targeted } \\
\text { Method: Sus-IT digital engagement survey, focus } \\
\text { groups }\end{array}$ & 23 \\
\hline $\begin{array}{l}\text { North Place Day Centre } \\
\text { (Surrey County Council), } \\
\text { Guildford }\end{array}$ & $\begin{array}{l}\text { Sample: computer and non-computer users } \\
\text { targeted } \\
\text { Method: Sandpits, Sus-IT digital engagement } \\
\text { survey }\end{array}$ & 18 \\
\hline \multicolumn{3}{|c|}{ University of the $3^{\text {rd }}$ Age groups } \\
\hline $\begin{array}{l}\text { University of the 3rd Age, } \\
\text { Long Eaton. }\end{array}$ & $\begin{array}{l}\text { Sample: all computer users targeted } \\
\text { Method: Sus-IT digital engagement survey }\end{array}$ & 44 \\
\hline $\begin{array}{l}\text { University of the 3rd Age, } \\
\text { Nottingham. }\end{array}$ & $\begin{array}{l}\text { Sample: all computer users targeted } \\
\text { Method: Sus-IT digital engagement survey }\end{array}$ & 52 \\
\hline $\begin{array}{l}\text { University of the } 3^{\text {rd }} \text { Age, } \\
\text { Sutton Bonnington }\end{array}$ & $\begin{array}{l}\text { Sample: All members of the group targeted } \\
\text { Method: Sus-IT digital engagement survey }\end{array}$ & 72 \\
\hline $\begin{array}{l}\text { University of the } 3^{\text {rd }} \text { Age, } \\
\text { Harrow }\end{array}$ & $\begin{array}{l}\text { Sample: established (2+ years) computer users } \\
\text { recruited } \\
\text { Method: Sus-IT digital engagement survey }\end{array}$ & 42 \\
\hline $\begin{array}{l}\text { University of the 3rd Age, } \\
\text { Ilkeston. }\end{array}$ & $\begin{array}{l}\text { Sample: all computer users targeted } \\
\text { Method: Sus-IT digital engagement survey }\end{array}$ & 28 \\
\hline \multicolumn{3}{|c|}{ Older peoples forums/panels } \\
\hline $\begin{array}{l}\text { 50+ Older People’s Forum, } \\
\text { Ilkeston. }\end{array}$ & $\begin{array}{l}\text { Sample: all computer users targeted } \\
\text { Method: Sus-IT digital engagement survey }\end{array}$ & 44 \\
\hline $\begin{array}{l}\text { 50+ Older People's Forum, } \\
\text { Long Eaton. }\end{array}$ & $\begin{array}{l}\text { Sample: all computer users targeted } \\
\text { Method: Sus-IT digital engagement survey }\end{array}$ & 105 \\
\hline $\begin{array}{l}\text { 50+ Older People’s Forum } \\
\text { Enfield }\end{array}$ & $\begin{array}{l}\text { Sample: established ( } 2+\text { years) computer users } \\
\text { recruited } \\
\text { Method: Sus-IT digital engagement survey }\end{array}$ & 28 \\
\hline $\begin{array}{l}\text { Hackney and City Older } \\
\text { Peoples Reference Panel }\end{array}$ & $\begin{array}{l}\text { Sample: all computer users targeted } \\
\text { Method: Sus-IT pictorial questionnaire }\end{array}$ & 10 \\
\hline $\begin{array}{l}\text { Why Not \& Older peoples } \\
\text { research group. }\end{array}$ & $\begin{array}{l}\text { Sample: established (2+ years) computer users } \\
\text { targeted } \\
\text { Method: Sus-IT digital engagement survey }\end{array}$ & 22 \\
\hline \multicolumn{3}{|c|}{ General community groups and organisations } \\
\hline $\begin{array}{l}\text { Café Scientifique and } \\
\text { Culturel, Edin’s Bar, }\end{array}$ & $\begin{array}{l}\text { Sample: established ( } 2+\text { years) computer users } \\
\text { targeted }\end{array}$ & 9 \\
\hline
\end{tabular}




\begin{tabular}{|c|c|c|}
\hline Nottingham. & Method: Sus-IT digital engagement survey & \\
\hline $\begin{array}{l}\text { Community Concern } \\
\text { Erewash, Cotmanhay. }\end{array}$ & $\begin{array}{l}\text { Sample: established (2+ years) users, clients of } \\
\text { CCE recruited } \\
\text { Method: Sus-IT digital engagement survey }\end{array}$ & 20 \\
\hline Leicestershire CareOnline & $\begin{array}{l}\text { Sample: computer dis-engagers targeted } \\
\text { Method: Case studies }\end{array}$ & 4 \\
\hline $\begin{array}{l}\text { Sikh Community, Royal } \\
\text { Leamington Spa. }\end{array}$ & $\begin{array}{l}\text { Sample: established ( } 2+\text { years) computer users } \\
\text { recruited } \\
\text { Method: Sus-IT digital engagement survey }\end{array}$ & 20 \\
\hline $\begin{array}{l}\text { Syresham Village } \\
\text { Community Computer } \\
\text { Club, Northamptonshire. }\end{array}$ & $\begin{array}{l}\text { Sample: All members of the group targeted } \\
\text { Method: Sus-IT digital engagement survey, focus } \\
\text { groups }\end{array}$ & 18 \\
\hline The Salvation Army & $\begin{array}{l}\text { Sample: all computer users targeted } \\
\text { Method: Sus-IT pictorial questionnaire }\end{array}$ & 6 \\
\hline Chelmsford Civic Society & $\begin{array}{l}\text { Sample: established (2+ years) computer users } \\
\text { targeted } \\
\text { Method: Sus-IT digital engagement survey }\end{array}$ & 8 \\
\hline $\begin{array}{l}\text { Transition Chelmsford } \\
\text { Team }\end{array}$ & $\begin{array}{l}\text { Sample: established ( } 2+\text { years) computer users } \\
\text { targeted } \\
\text { Method: Sus-IT digital engagement survey }\end{array}$ & 12 \\
\hline \multicolumn{3}{|c|}{ Conferences/Events } \\
\hline $\begin{array}{l}\text { Festival of Social Sciences } \\
\text { Event, Cotmanhay }\end{array}$ & $\begin{array}{l}\text { Sample: All members of the group targeted } \\
\text { Method: Sus-IT digital engagement survey }\end{array}$ & 13 \\
\hline $\begin{array}{l}\text { Digital Inclusion event 2: } \\
\text { Chelmsford. }\end{array}$ & $\begin{array}{l}\text { Sample: older adults and professionals interested } \\
\text { in digital inclusion issues. } \\
\text { Method: Problem-solving workshop, Sus-IT } \\
\text { digital engagement survey }\end{array}$ & 66 \\
\hline \multicolumn{3}{|c|}{ Educational and learning establishments } \\
\hline Middlesex University & $\begin{array}{l}\text { Sample: established ( } 2+\text { years) computer users } \\
\text { recruited } \\
\text { Method: Sus-IT digital engagement survey }\end{array}$ & 16 \\
\hline $\begin{array}{l}\text { Dundee User Centre, } \\
\text { School of Computing, } \\
\text { University of Dundee }\end{array}$ & $\begin{array}{l}\text { Sample: established ( } 2+\text { years) computer users } \\
\text { targeted } \\
\text { Method: Sus-IT digital engagement survey }\end{array}$ & 38 \\
\hline Angus College, Arbroath & $\begin{array}{l}\text { Sample: established ( } 2+\text { years) computer users } \\
\text { targeted } \\
\text { Method: Sus-IT digital engagement survey }\end{array}$ & 25 \\
\hline Angus College, Forfar & $\begin{array}{l}\text { Sample: established ( } 2+\text { years) computer users } \\
\text { targeted } \\
\text { Method: Sus-IT digital engagement survey }\end{array}$ & 33 \\
\hline Angus College, Kirriemuir & $\begin{array}{l}\text { Sample: established (2+ years) computer users } \\
\text { targeted } \\
\text { Method: Sus-IT digital engagement survey }\end{array}$ & 17 \\
\hline $\begin{array}{l}\text { Destinations Learning } \\
\text { Centre and Internet Cafe, } \\
\text { Saltburn by Sea }\end{array}$ & $\begin{array}{l}\text { Sample: established (2+ years) targeted } \\
\text { Method: Sus-IT digital engagement survey, in- } \\
\text { depth interviews }\end{array}$ & 15 \\
\hline
\end{tabular}

Table 2: Age range of participants

\begin{tabular}{|l|l|l|}
\hline Age range & $\begin{array}{l}\text { Number of } \\
\text { participants }\end{array}$ & Percentage \\
\hline
\end{tabular}




\begin{tabular}{|l|c|c|}
\hline $50-59$ & 39 & $12 \%$ \\
\hline $60-69$ & 134 & $41 \%$ \\
\hline $70-79$ & 103 & $32 \%$ \\
\hline $80-89$ & 38 & $12 \%$ \\
\hline Question not answered & 9 & $3 \%$ \\
\hline Total & $\mathbf{3 2 3}$ & $\mathbf{1 0 0 \%}$ \\
\hline
\end{tabular}

Figure 3: Range of computer related tasks undertaken by participants

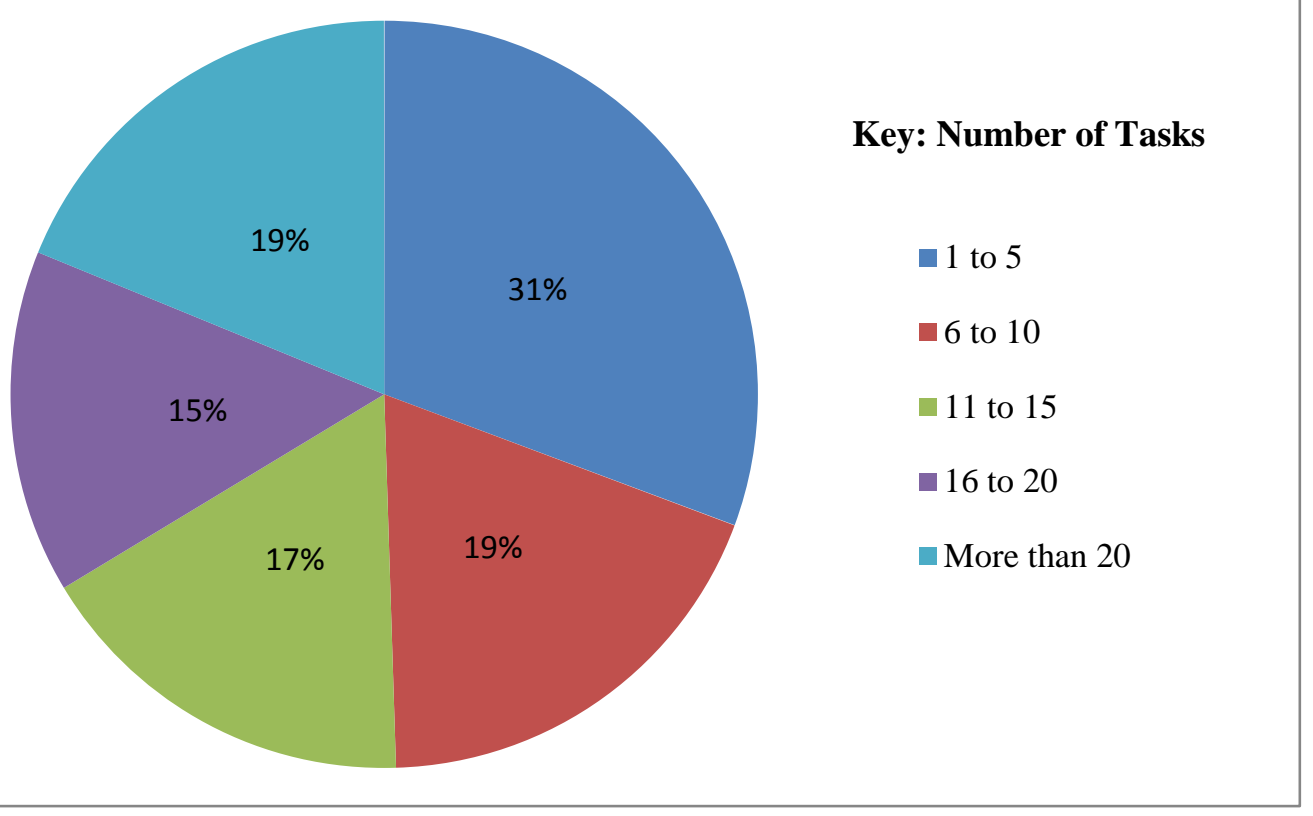

Source: Sus-IT Digital Engagement Survey

Table 4: Q8. If you need help when using technology, how often do you use the following sources? 


\begin{tabular}{|l|l|l|l|l|l|}
\hline Source of support & $\mathbf{1}$ & $\mathbf{2}$ & $\mathbf{3}$ & $\mathbf{4}$ & $\begin{array}{l}\mathbf{5} \\
\text { (Always) }\end{array}$ \\
\hline Friends and family & 9 & 18 & 21.4 & 19.2 & 32.2 \\
\hline Trial and error & 9.1 & 11.2 & 21.6 & 25.5 & 32.8 \\
\hline $\begin{array}{l}\text { Staff at computing } \\
\text { class }\end{array}$ & 21.7 & 14.5 & 16.7 & 17.2 & 29.9 \\
\hline Internet & 34.3 & 15.9 & 19.8 & 10.6 & 19.3 \\
\hline OS help files & 37.9 & 15.7 & 23.2 & 11.6 & 11.6 \\
\hline Books & 39.9 & 14.6 & 18.5 & 15.2 & 11.8 \\
\hline Software help files & 46.5 & 14.7 & 16.5 & 8.8 & 13.5 \\
\hline Social networking & 68.8 & 17.2 & 7.3 & 3.3 & 3.3 \\
\hline
\end{tabular}

Source: Sus-IT Digital Engagement Survey

\begin{tabular}{|l|l|}
\hline \multicolumn{2}{|c|}{ Table 5: Data Sources Key } \\
\hline \multicolumn{1}{|c|}{ Location } & \multicolumn{1}{c|}{ Method } \\
\hline SALT $=$ Saltburn & FG = Focus group \\
\hline DUN = Dundee & INT = In-depth interviews \\
\hline MID = Midlands & ST - Storytelling \\
\hline LON = London & DE - Digital Engagement Survey \\
\hline
\end{tabular}

